\title{
Properties of Alumina Coated with Hydroxyapatite Nano-Sol
}

\author{
Seung Hyun Lee ${ }^{1}$, Myeong Hun Bae ${ }^{1}$, Nam Lyon Kang ${ }^{2}$, Su Chak Ryu ${ }^{2}$ \\ ${ }^{1}$ Pusan National University, Department of Nano Fusion Technology, Miryang 627-706, South Korea \\ ${ }^{2}$ Pusan National University, Department of Applied Nanoscience, Miryang 627-706, South Korea
}

Copyright (C) 2014 Horizon Research Publishing All rights reserved.

\begin{abstract}
In this study, This study report the preparation of alumina matrix coated with hydroxyapatite and their evaluation as biomaterials. The first hydroxyapatite powder is made by Dry Method. And then hydroxyapatite sol is made by attrition mill due to decreasing the size of hydroxyapatite. the second prepared alumina was coated with HAp sol for 10-50 seconds. And then, the structures tested their mechanical and biological properties. First, Compressive strength and hardness evaluates as measuring the mechanical properties. According to adding the HAp, Compressive strength shows increased tendency and indicates up to a maximum value of $122 \mathrm{MPa}$ in this study. However, hardness indicates low value which is that of Monolithic alumina, because this hardness value is measured HAp located on the surface of alumina. Second, measuring the biological properties is observed Calcium growth on the structure surface. When bathed in simulated body fluid (SBF), calcium growth was observed for both structures. Notably, MC3T3-E1 pre-osteoblastic cells grew on disks made up the alumina matrix coated with HAp and cell proliferation enhancements were similar to pure hydroxyapatite. These results suggest that structure is potentially useful as an artificial bone material.
\end{abstract}

Keywords Grain Boundaries, .Mechanical Properties, $\mathrm{Al}_{2} \mathrm{O}_{3}$, Biomedical Applications, Hydroxyapatite

\section{Introduction}

Recent developments in medical technology generate aging. As a result, bone damage and degradation are becoming more frequent. Concurrently, great progress has been made in developing bioceramics for bone repair and replacement.

Among bioceramics, alumina is well known as typical bioceramics. Alumina has strong bond between aluminium and oxygen, as a result among oxide, it has high hardness and chemically stable. Therefore, it is widely used as structural ceramics due to wear resistance and corrosion resistance.[1-3]

However, alumina has low Fracture Toughness. To apply the alumina at the variety of regions is required improving the mechanical and biological properties.

Therefore, producing the metal/ceramic complex[4-8] or using the coating method with bioglass[9] which is well known as osteoconductive materials has currently been studied. [10,11]

However, metals run the risk of being corroded in the human body. When applying the coating method with bioglass, that is often failed. Some researchers suspect that $\mathrm{Al} 3+$ ion come to the surface which is facing the bioglass. As a result, the surface of bioglass is not fixed due to contaminating $[12,13]$. Furthermore, when biomaterial is inserted in vivo, bacterial infection is one of the main problems. [14-17]

Material which has ability of solving the above problems is needed. So, hydroxyapatite(HAp) which has similar composition to human bone is selected. HAp can be used directly in the body. [18-21] Artificially synthesised HAp has the chemical formula of $\mathrm{Ca}_{10}\left(\mathrm{PO}_{4}\right)_{6}(\mathrm{OH})_{2}$, and has outstanding biocompatibility and bioaffinity leading to rapid growth of osseous tissue. Among metals, titanium alloys have also attracted attention as biomaterials owing to their outstanding mechanical properties and biocompatibility. [22-24]

In this study, weakness of HAp compensate by using aluminium oxide (alumina) which has exceptional physical strength. As a result, alumina powder and HAp powder are transformed into small particles upon using attrition and ball milling. Samples were prepared from alumina by either mixing or coating it with HAp: one alumina matrix was prepared with $1-10 \mathrm{wt} \% \mathrm{HAp}$ and the other was coated with HAp for $10-50$ s. Their mechanical and biological properties were compared with those of pure alumina. Their bioactivity was confirmed through experiments in simulated body fluid (SBF) and cell proliferation tests, suggesting potential application as artificial osseous tissue. 


\section{Materials and Methods}

\subsection{Preparation of Alumina and HAp Powders}

To produce the structures, HAp and alumina (32015-1250, JUNSEI, Japan) were used. In order to obtain high-purity HAp whose stoichiometry mixing ratio is 1.67 , calcium carbonate and phosphoric acid were mixed for 24 hours in order to obtain a uniform mixture. After drying, this mixture was sintered for 4 hours at $1350^{\circ} \mathrm{C}$ with rates of temperature increase and decrease of $5^{\circ} \mathrm{C} / \mathrm{min}$ and $4^{\circ} \mathrm{C} / \mathrm{min}$, respectively. The HAp powder obtained was crushed by ball milling and was sieved with a 325 mesh (particle diameter $\leqq 45 \mu \mathrm{m}$ ).

Figure 1. shows a flow chart of HAp preparation and mixing process. Alumina powder was crushed by attrition mill at $400 \mathrm{rpm}$ for 12 hours and then freeze dried.

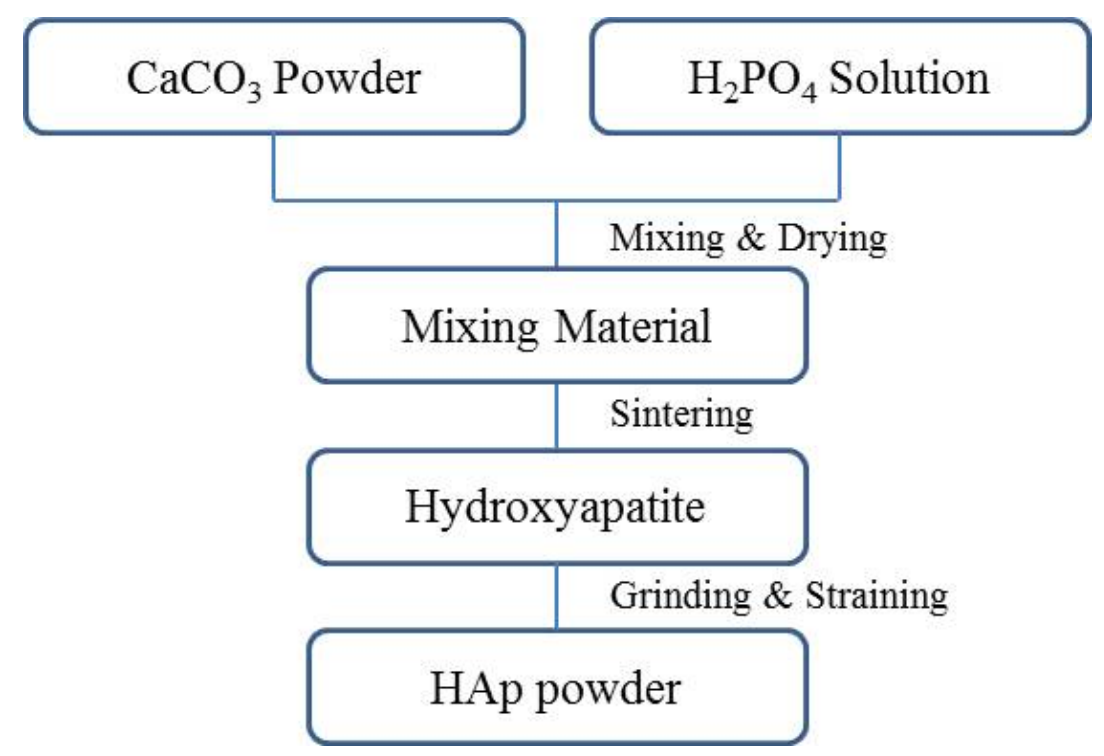

Figure 1. flow chart of HAp preparation and mixing process

\subsection{Sample Preparation}

Figure 2 is a complex production process using a coating. After Alumina powder is casting by a mold, which is sintered For 4 hours to $1500^{\circ} \mathrm{C}$. The temperature raising rate is $5^{\circ} \mathrm{C} / \mathrm{min}$ and cooling rate of $4^{\circ} \mathrm{C} / \mathrm{min}$ was sintered.

Sintered alumina matrix is conducted dipping method in HAp solution for 10-50 seconds. HAp solution which consists $100 \mathrm{~g} \mathrm{H}_{2} 0,50 \mathrm{~g} \mathrm{HAp}$ and $300 \mathrm{~g}$ zirconia ball whose size is $2 \mathrm{~mm}$ was crushed by attriction mill of 500rpm, for 4 hours

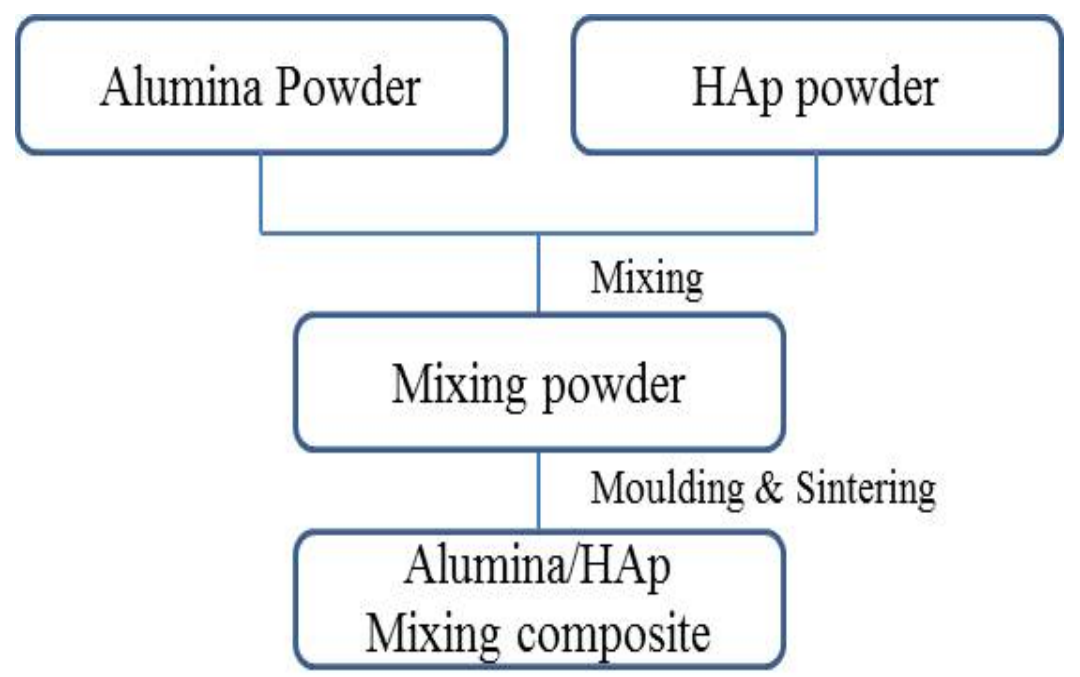

Figure 2. Flow chart showing the process for producing Alumina matrix coated HAp 


\subsection{Physical Strength Measurement}

The physical strength of the structures was recorded after sintering the mixture in moulds. Compressive strength was measured using samples from a round mould, $10 \mathrm{~mm}$ in diameter and $10 \mathrm{~mm}$ high. In this case, a universal testing machine (SMTEST, SMB-001-5T, Korea) was employed. Hardness was measured using a Vickers microhardness tester (FM700, Future Tech, Japan).

\subsection{Measuring the Density and Total Porosity of HAp}

To Confirm permeated quantity of HAp at alumina matrix, According to the dipping time, Density and Pore volume are measured by AccuPyc II 1340(Micromeritics, USA). Each part is measured per five times. The results of this part make equal and is indicated as graph. The structures were employed for measurement of physical strength.

\subsection{Observations of the Activity of the Sample Surface in SBF Solution}

To confirm the bioactivity of the alumina matrix coated with hydroxyapatite in the body, samples were immersed in an SBF solution, whose inorganic ionic concentrations are similar to components in human blood plasma/body fluids. After four weeks, the sample surfaces were observed by field emission scanning electron microscopy (FE-SEM, HITACHI-S4700, HITACHI, Japan). Also, to confirm the quantity of $\mathrm{Ca}$ ion which is adsorbed on surface of samples, $\mathrm{Ca}$ ion contents on the surface of samples is measured by energy-dispersive X-ray spectroscopy(EDX, HITACHI-S4700, HITACHI, Japan).

\subsection{Cell Culture Experiments on Alumina Matrix Coated with Hydroxyapatite}

\subsubsection{Cell Culture}

Cell cultures were prepared in an incubator under an atmosphere of $5 \% \mathrm{CO}_{2}$ at $37^{\circ} \mathrm{C}$ for 24 hours with a culture fluid consisting of $\alpha$-minimal essential medium ( $\alpha$-MEM, Wel gene) with $10 \%$ heat-activated foetal bovine serum, (FBS, Sigma) and $1 \%$ antibiotic antimycotic solution (10,000 units penicillin, $10 \mathrm{mg}$ streptomycin, and $25 \mathrm{~g}$ Amphotericin B per mL, Sigma).

If cell density rose, the culture was washed in two steps, first with phosphate buffered saline (PBS, GIBCO) and then with trypsin $\left(0.05^{\circ} \mathrm{C}\right.$ trypsin, $0.02^{\circ} \mathrm{C}$ EDTA in Hank's balanced salt solution without calcium and magnesium) for 4 minutes.

After detaching the cells, the subcultures progressed on the logarithmic scale, and experiments on the subcultured cells were conducted 10 times faster than the progress of the cultures on the logarithmic scale.

\subsubsection{Cell Proliferation Experiments}

For cell proliferation experiments on the alumina matrix coated with hydroxyapatite, Cell differentiation experiments were performed using pre-osteoblasts from mouse embryo cranium tissue, MC3T3-E1, that were added to the cell culture medium, $\alpha$-MEM, along with $10 \%$ FBS (Sigma) and $1 \%$ penicillin/streptomycin $(\mathrm{v} / \mathrm{v})$. Cell culture progressed in the moist culture medium under an atmosphere of $5 \% \mathrm{CO}_{2}$, at $37^{\circ} \mathrm{C}$ for $2-3$ days. When cells reached $80 \%$ confluence, Separation steps were performed using PBS containing $0.25 \%$ trypsin and $0.02 \%$ ethylendiamine (EDTA).

For subcultures, A new culture organisation was used. Cell proliferation experiments were conducted under the same conditions as cell culture experiments. MC3T3-E1 cells located on the surface of the alumina matrixes coated with hydroxyapatite were cultured at a density of $1 \times 10^{4}$ cells/well in a plate of 48 wells. Live cells were counted using the tetrazolium reduction method (WST-8, 2-(2-methoxy-4-nitrophenyl)-3-(4-nitrophenyl)-5-(2,4-disul fo-phenyl)- $2 H$-tetrazolium, Dojindo Lab., Kumamoto, Japan); Consequently, Cell proliferation was proportional to the metabolic reaction products obtained with the WST-8 assay.

The WST-8 assay was conducted as follows: WST-8 was added to a 96-microwell plate and cells were grown for 4 hours in an incubator under normal conditions. The changes in the samples were observed after 1, 7 and 14 days by measuring the absorbance at $450 \mathrm{~nm}$ using an ELISA Reader (Molecular Devices, USA).

\section{Results and Discussion}

\subsection{Effect of Compressive Strength on the Material}

The evaluated mechanical properties of HAp-coated alumina are shown in Figures 3. 0 second sample is only alumina sample which is control group in this experiment. The compression strength increases with dipping time in the HAp solution. Of the many mechanisms proposed, this result is related with pore size and porosity. [25,26]

Also, Figures 4 is supported this claim. That is shown the decreased tendency. According to permeating the HAp, Open pore in the alumina matrix is to show reduced tendency from $0.7570 \mathrm{~cm}^{3}$ at 0 second to $0.7498 \mathrm{~cm}^{3}$ at 50 second.

As a result, HAp infiltration into alumina increases given the blow holes in the sintered alumina body. Therefore, inner of alumina matrix becomes increasingly dense, resulting in its greater density. This leads to improvements in compression strength.

In other words, densification by sintering leads to increased physical strength and has a great effect on compression strength. 


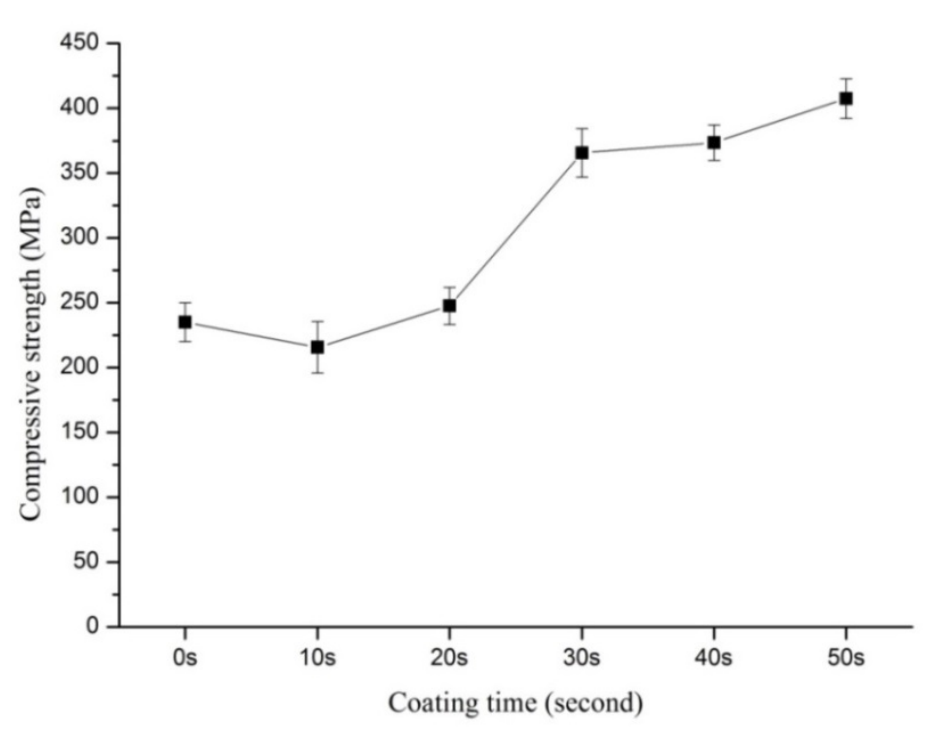

Figure 3. Compressive strength of alumina matrix coated with hydroxyapatite

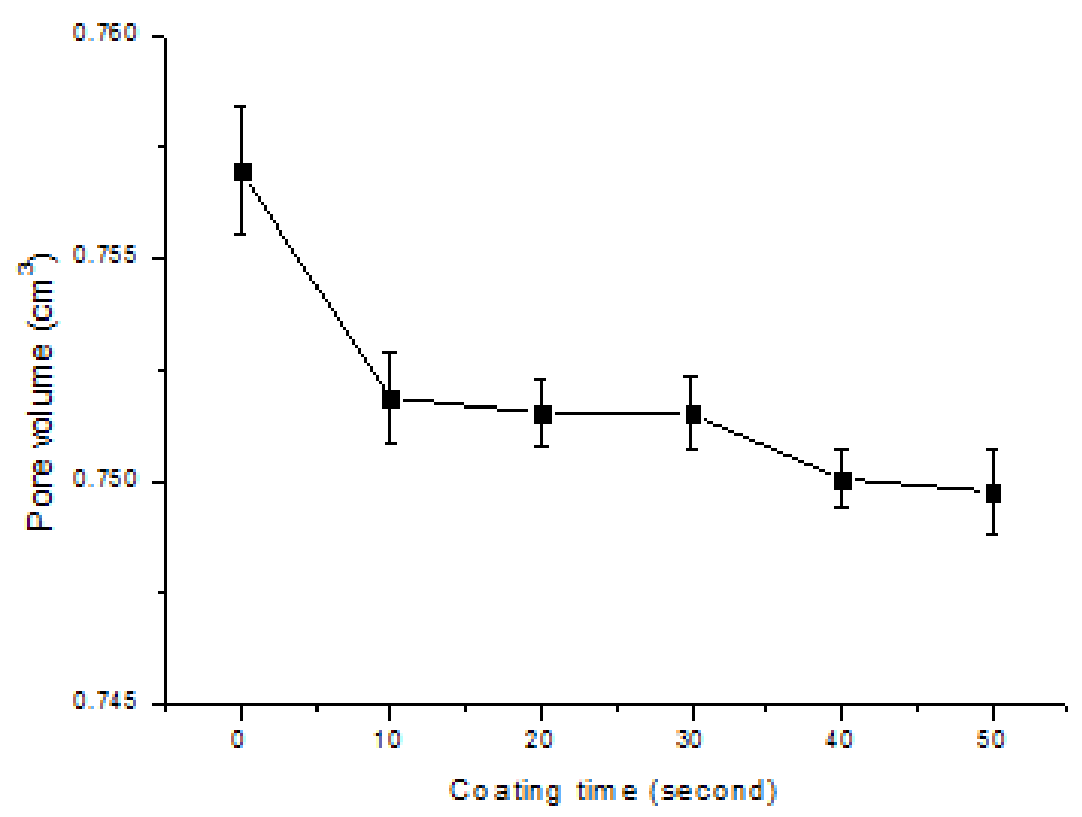

Figure 4. Pore volume of alumina matrix coated with hydroxyapatite

\subsection{Effect of Hardness on Alumina Matrix}

The hardness results of alumina matrix coated with hydroxyapatite are shown in Figure 5. The hardness of pure, non-coated alumina sintered at $1500^{\circ} \mathrm{C}$ is approximately $507.6 \mathrm{HV}$; the hardness of structures is lower when process under similar conditions. When measuring the hardness of compounds coated with HAp, it was the hardness of HAp that was measured. 


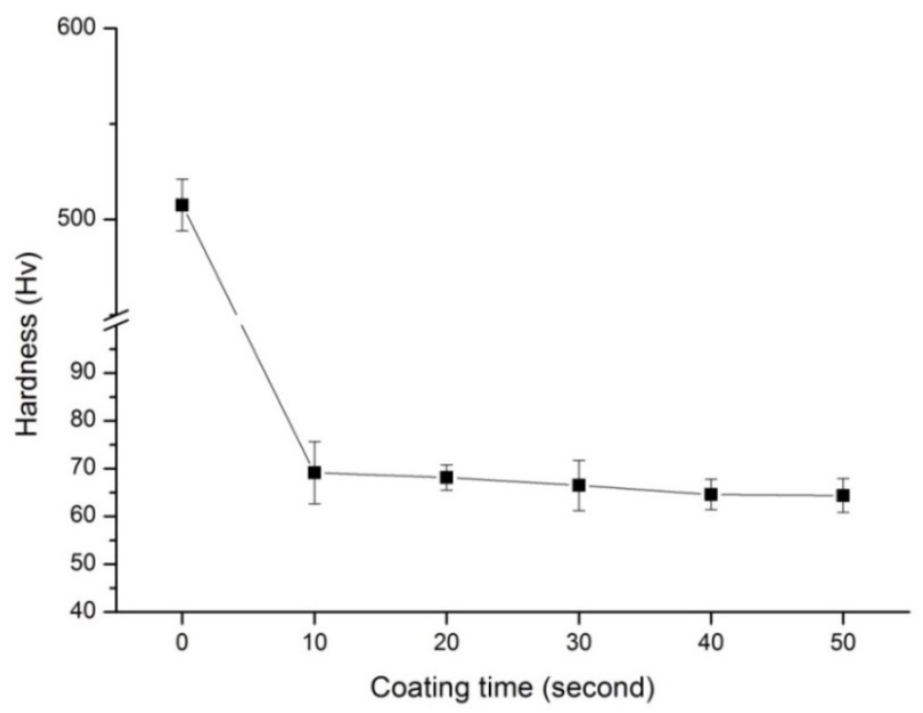

Figure 5. Hardness of alumina matrix coated with hydroxyapatite

\subsection{Activity of Alumina Matrix Coated with Hydroxyapatite in SBF}

Figure 6 shows a picture obtained from the surface of the alumina matrix coated with hydroxyapatite left in SBF for four weeks. Uncoated sintered alumina shows no surface activity, as is expected. That is equal phenomenon of the surface of normal Alumina sintering body. A layer of Ca ions appears on the samples coated with HAp. When coated with HAp for $50 \mathrm{sec}$, the whole surface is covered with $\mathrm{Ca}$ ions.

Figure 7 shows a quantity of $\mathrm{Ca}$ ion on the sample surface. 0 second sample is indicated that quantity of $\mathrm{Ca}$ ion is zero weight percent. The other samples are indicated that quantity of ca ion is 32-34 weight percent. Above result is related with ions located in HAp. HAp has many ions, such as $\mathrm{NA}^{+}, \mathrm{K}^{+}, \mathrm{Mg}^{2+}, \mathrm{Sr}^{2+}, \mathrm{Cl}^{-}, \mathrm{F}, \mathrm{HPO}^{2-}$, etc [27] These ions are exchanged with $\mathrm{Ca}$ ion which is located in SBF solution, and then, $\mathrm{Ca}$ layer is growing and making some structures, as a result, Ca structure is able to replace and recover the loss part.
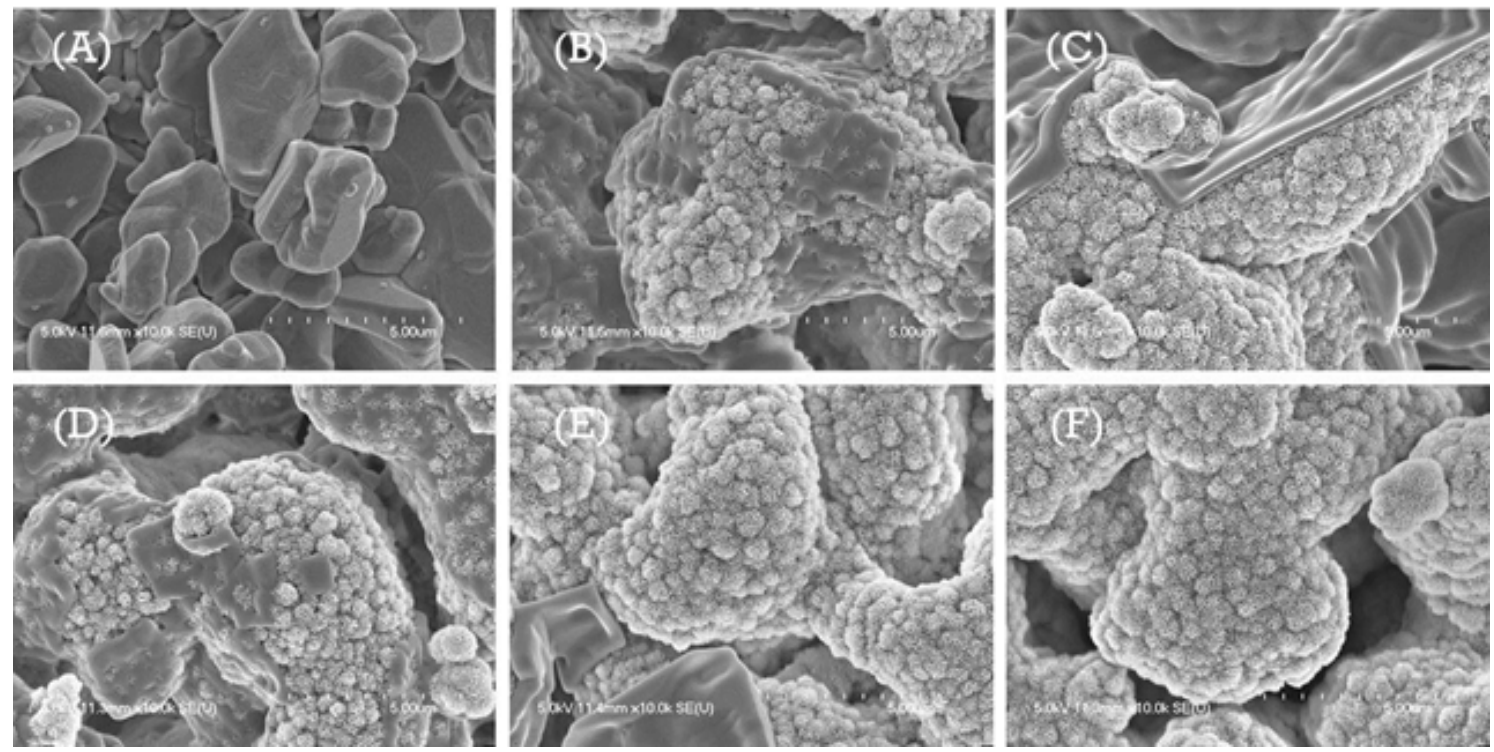

Figure 6. SEM images of alumina matrix coated with hydroxyapatite after four weeks in SBF. Coating times: (A) $0 \mathrm{~s}$, (B) $10 \mathrm{~s}$, (C) $20 \mathrm{~s}$, (D) $30 \mathrm{~s}$, (E) $40 \mathrm{~s}$, and (F) $50 \mathrm{~s}$. 


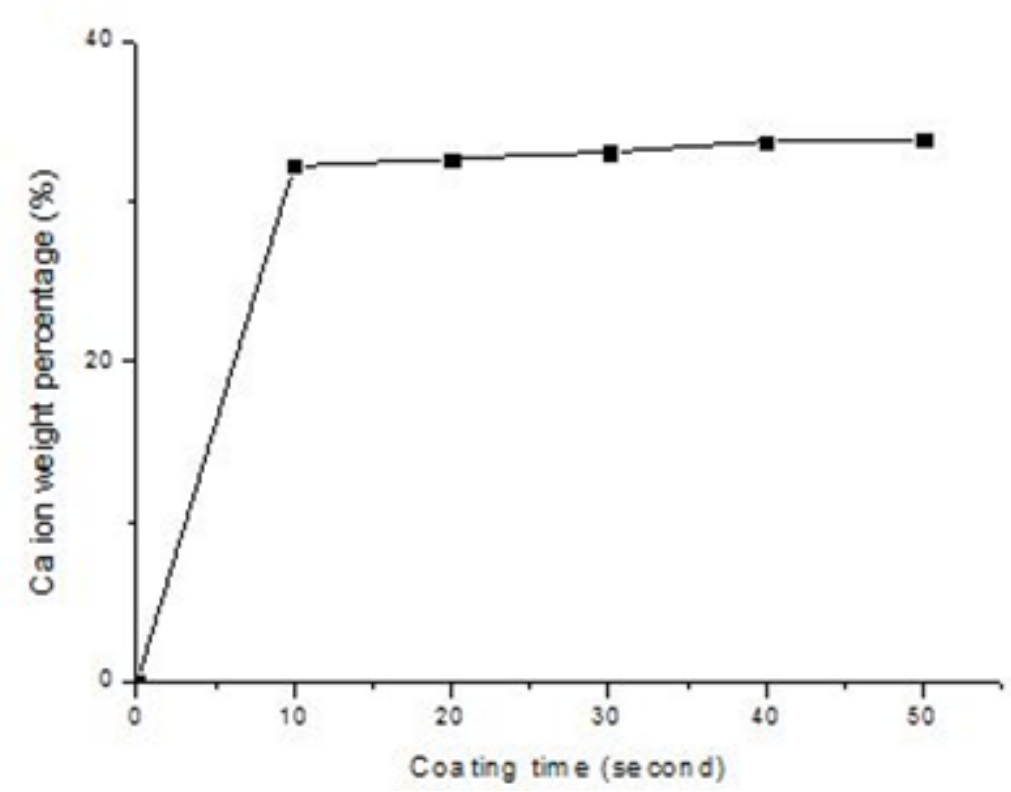

Figure 7. Ca ion weight percent of alumina matrix coated with hydroxyapatite

\subsection{Cell Proliferation on Alumina Matrix Coated with Hydroxyapatite}

Even when HAp is not added, control experiments on uncoated sintered alumina show that cell proliferation is somewhat increased. However, the cell proliferation of structures is increased more than that of uncoated, sintered alumina.

Cell proliferation is the highest for the alumina matrix coated with hydroxyapatite. However, a correlation with the HAp coating time is not apparent in Figure 8, which shows the MC3T3-E1 cell proliferation rate measured on alumina matrix coated with hydroxyapatite

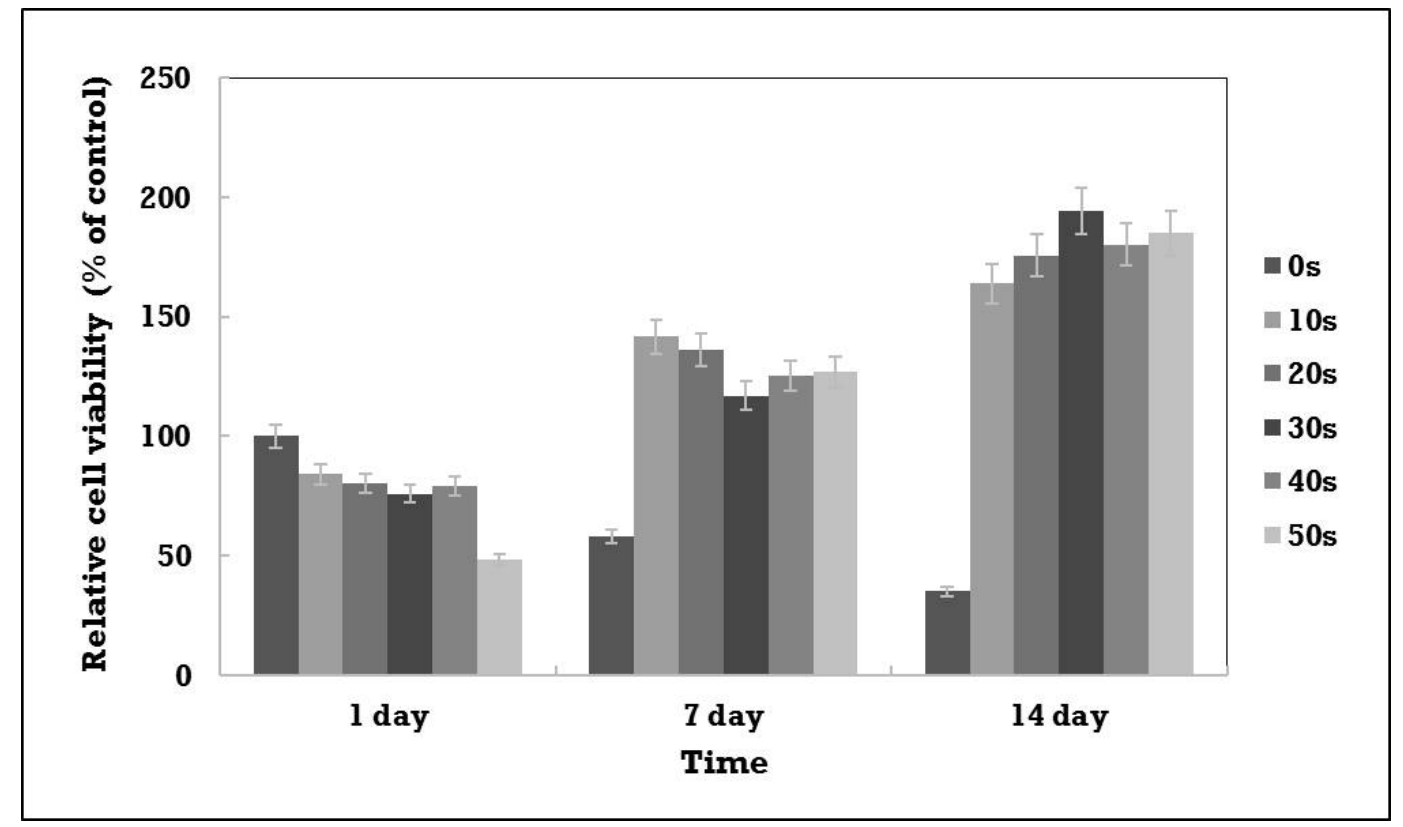

Figure 7. Relative cell viability of alumina matrix coated with hydroxyapatite on MC3T3-E1 for 14 days 


\section{Conclusions}

As biomaterials with combining desirable properties of bioactivity, biocompatibility, and excellent physical strength, this study proposes two types of alumina matrix coated with hydroxyapatite. These two types of structures have dissimilar properties given the different processing steps.

Compression strengths of alumina matrix coated with hydroxyapatite are lower than those of pure alumina. The addition of HAp leads to increased strength up to a maximum value of $122 \mathrm{MPa}$, which demonstrates that sintering of alumina is not complete at $1350^{\circ} \mathrm{C}$. Alumina matrix coated with hydroxyapatite tends to exhibit increased compressive strength. The change in compressive strength is related the densification of the alumina matrix coated with hydroxyapatite, which densified with increasing coating time up to a maximum of $407 \mathrm{MPa}$. A maximum hardness of $504 \mathrm{HV}$ was measured for the alumina matrix coated with hydroxyapatite when sintered at higher temperatures.

In SBF activity experiments, the surface of uncoated sintered alumina did not change, whereas the surfaces of the alumina matrix coated with hydroxyapatite showed increased activity and $\mathrm{Ca}$ ions were observed to have been produced.

Results of cell proliferation show that normal cell proliferation occurs in all structures. With increasing HAp content, mixed structures tend to show increased cell proliferation, and coated structures show a significant increase in cell proliferation rates.

Based on the results of the above experiments, it is suggested that the HA-coated alumina composites can be used as a resorbable biomaterial for osseous tissue.

\section{REFERENCES}

[1] J. Knuuttila, S. Ahmaniemi, E. Leivo, P. Sorsa, P. Vuoristo, T. Mantylat, Wet abrasion and slurry erosion resistance of sealed oxide coatings, Proceedings of the 15th International Thermal Spray Conference, Vol. 1, 25-29 May 1998, Nice, France, pp. $145-150$.

[2] A. Giroud, C. Jouanny, J.L. Heuze, F. Gaillard, P. Guiraldenq, Friction and corrosion behavior of different ceramic coatings oxides. obtained by thermal spray for qualification tests in sea water, Proceedings of the 15th International Thermal Spray Conference, Vol. 1, 25-29 May 1998, Nice, France, pp. 211-216.

[3] C. Ding, J. Li, L. Zhang, X. Yu, Wear evaluation of plasma sprayed oxide and carbide coatings, Proceedings of the 15 th International Thermal Spray Conference, Vol. 1, 25-29 May 1998, Nice, France, pp. 275-279.

[4] Moffa JP. Alternative dental casting alloys. Dent Clin North Am 1983;27:733-46.

[5] Anusaviee K J, Twiggs SW, DeHoff PH, Fairhurst CW.
Correlation of thermal compatibility data for porcelain-metal systems. J Dent Res 1982;61:419-22.

[6] Anusaviee KJ, Shen C, Hashinger D, Twiggs SW. Interactive effect of stress and temperature in creep of PFM alloys. J Dent Res 1985;64: 1094-9.

[7] Bertolotti RL. Calculation of interracial stress in porcelain-fusedto- metal systems. J Dent Res 1980;59:1972-7.

[8] Craig RC, ed. Restorative dental materials. 7th ed. St Louis: CV Mosby Co, 1985:454, 455.

[9] Clark A.E., Hench L.L., Calcium phosphate formation on sol-gel derived bioactive glasses,J. Biomed. Mater. Res., 28, pp693-8 (1994)

[10] Hench L.L., Sol-gel materials for bioceramic applications, Curr. Opin. Solid State Mater. Sci., 2, pp604-10 (1997)

[11] Hench L.L., Wilson J., Surface-active biomaterials, Science, 226, pp630-6 (1984)

[12] Hamadouche M, Nizard RS, Meunier A, Blanchat C, Masquelier, P, Sedel L.Osteocon ductive properties of bioactive glasses in a bulk form and as a coating on alumina.In: Le Geros RZ, Le Geros JP, editors.Bioceramic s II.New Jersey: World Scientific Publishing, 1998.p.427-30.

[13] Gross U, Schmitz H-J, Strunz V.Bioceram ics.In: Ducheyne P, Lemons JE, editors. Material characteristics versus in vivo behavior: surface bioactivity of bioactive glass, aluminium oxide, and titanium in a living environment.New York, NY: The New York Academy of Science, 1988.p.211-26.

[14] Fitzgerald, R. H., Jr. Infections of hip prostheses and artificial joints. Infect. Dis. Clin. N. Am. 3:329-338; 1989.

[15] Gristina, A. G.; Kollcin, J. Total joint replacement and sepsis. J. Bone Joint Surg. 65A:128-134; 1983.

[16] Sugarman, B.; Young, E. J. Infections associated with prosthetic devices: magnitude of the problem. Infect. Dis. Clin. N. Am. 3:187-199; 1989.

[17] An, Y. H.; Friedman, J. R. Prevention of infection in total joint arthroplasty. J. Hosp. Infect. 33:93-108; 1996.

[18] de Bruijn JD, van Blitterswijk CA, Davies JE. Initial bone matrix formation at the hydroxyapatite interface in vitro. $\mathrm{J}$ Biomed Mater Res 1995;29(1):89\}99.

[19] Jarcho M. Calcium phosphate ceramics as hard tissue prosthetics. Clin Orthop 1981;157:259\}78.

[20] Jarcho M. Retrospective analysis of hydroxyapatite development for oral implant applications. Dent Clin North Am 1992; 36(1):19\}26.

[21] Okumura M, Ohgushi H, Dohi Y, Katuda T, Tamai S, Koerten HK, Tabata S. Osteoblastic phenotype expression on the surface of hydroxyapatite ceramics. J Biomed Mater Res 1997;37:122\}9.

[22] Oh, I.H., et al., 2003. Mechanical properties of porous titanium compacts prepared by powder sintering. Scripta Mater. 49, 1197-1202.

[23] Niinomi, M., 2003. Recent research and development in titanium alloys for biomedical applications and healthcare goods. In: STAM, vol. 4, pp. 445-454. 
[24] Niinomi, M., 2005. Japanese research and development in metallic biomedical, dental and healthcare materials. JOM 57, $18-24$.

[25] 'W. B. Crandall, D. H. Chung, and T. J. Gray, "The Mechanical Properties of Ultra-Fine Hot-Pressed Alumina"; pp. 349-76 in Mechanical Properties of Engineering Ceramics. Edited by W. W. Kriegel and H. Palmour 111.
Interscience Publishers, New York, 1961.

[26] B. Binns and P. Popper, "Mechanical Properties of Some Commercial Alumina Ceramics," Proc. Br. Cerum. Soc., 6, 71-82 (1966).

[27] Vallet-Regi' M. Introduction to the world of biomaterials. Ann Quim Int Ed 1997;93:S6-S14. 